\title{
INTERVIEW STUDY ON THE AGILE DEVELOPMENT OF MECHATRONIC SYSTEMS
}

\author{
Goevert, Kristin (1); Heimicke, Jonas (2); Lindemann, Udo (1); Albers, Albert (2) \\ 1: Technical University of Munich; 2: Karlsruhe Institute of Technology
}

\begin{abstract}
In order to be as responsive as possible to changes in the dynamic context of mechatronic system development, companies are increasingly integrating agile approaches into their development processes. They are confronted with the challenges of adapting approaches that originate in software development to the conditions of physical development, without neglecting the experiences gained over many years regarding product and process knowledge. In addition, agile development approaches must be integrated into existing processes through a systematic implementation strategy. In order to gain an initial understanding of the current situation in mechatronic companies with regard to agile development approaches, an interview study was conducted with 18 participants from real development practice. This could show that the companies in mechatronic system development are currently at the beginning of agile transformation and need approaches that are modelled on the basis of real development projects and are best possible tailored to the needs of these companies through a clear technical orientation. The findings gained are not universally valid, but represent a basis for further research work.
\end{abstract}

Keywords: Agile, Interview Study, Design process, Early design phases, Design methods

\section{Contact:}

Goevert, Kristin

Technical University of Munich

Product Development and Lightweight Design

Germany

kristin.goevert@tum.de

Cite this article: Goevert, K., Heimicke, J., Lindemann, U., Albers, A. (2019) 'Interview Study on the Agile 


\section{INTRODUCTION}

In many companies agile development is increasingly used in mechatronic product development and agile methods from software development are transferred (Cooper and Sommer, (2016), Goevert et al. (2018)). Agile development means reacting quickly and adaptably in uncertain situations and in a dynamic environment (Hofert, 2016). On the one hand agile development is often associated with changes of costumer needs can be better implemented, faster development, and the team communication is improved (Cooper and Sommer, 2016). On the other hand, the integration of agile development is often related with challenges in existing companies. Due to standards, defined development processes contradictory regulations, and limits often exist in the companies (Schuh et al., 2018).

In addition to the challenges on the process side, the complexity of products is increasing, the desire for more individualized products is growing, and product life cycles are becoming shorter (Reichwald and Piller, 2009). All of this leads to uncertainties, which companies nowadays face with agile approaches. However, agile development does not only mean to apply agile methods, but also to act according to the agile principles and values of the agile mainfest and to develop a corresponding mindset (Schaaf, 2017). Based on this, an approach is needed that consider and uses the potentials and limits of agile approaches in mechatronic system development and implementation. In order to develop this, an understanding of problems in the agile development of mechatronic systems must be created first. Although there are many contributions dealing with the topic of agile development, these mostly address the agile development of software.

The aim of this research project is to use an interview study to determine the current situation in industry regarding agile development and to identify existing challenges and potential for further research in the field of mechatronic system development.

\section{LITERATURE BACKGROUND}

This section gives an overview of the literature background in agile development, distinguishes agile development from classical development, summarizes implementation approaches and describes agile studies from practice.

\subsection{Agile mechatronic development}

To face the uncertainties in the development context and to identify the continuous safeguarding of development results as well as the objectives of customers and users (Albers et al., 2018) through a multitude of short iterations, companies use agile approaches in the product development process (Denning, 2013). These are based on values and principles from the Agile Manifesto, which a committee of well-known software developers has manifested as the basis for successful development projects according to a retrospective best practice approach (Fowler and Highsmith, 2001). Since then, many agile approaches have emerged that have found their way more or less widely into mechatronic system development (Schmidt et al., 2018). Particularly in early development phases, in which the limits of the physicality of mechatronic products do not hinder fast and short iteration cycles, approaches such as Design Thinking (Plattner et al., 2011) or Scrum (Schwaber and Sutherland, 2017) support development teams in the customer-oriented development of product concepts (Schmidt et al., 2017). This is done through a series of easy to implement practices aimed at rapid, uncomplicated and customer-focused development with the aim of continuously optimising the value the subsequent product will have for the customer (Denning, 2013). Agility in the field of mechatronic system development can therefore be understood as "the capability to discover and understand changing product requirements, and being able to quickly consider these changes while making progress in developing the product" (Rebentisch et al., 2018). In the transformation of development teams, departments and organizations, however, a distinction is made in the literature between "doing agile" and "being agile", whereby the former is understood as a collection of measurable and observable activities and will have short-term effects. Without an agile mindset that changes culture, people and communication and is summarized under the term "Being agile", however, agility in an organization cannot be implemented in the long term (Ranganath, 2011). 


\subsection{Plan-driven development vs. agile product development}

With regard to the procedure in development and the handling of different elements in the development process, a distinction is made between plan-driven development and agile approaches for the organization of development projects (Rundle and Dewar, 2006). In addition to the agile approaches already mentioned, Waterfall, the RUP Process and the V-Model (Petersen and Wohlin, 2010) are wellknown representatives in the area of plan-driven development approaches. Thorough recording requirements, rigid and sequences of activities with extensive documentation of development results and continuous compliance with hard quality requirements are linked to these approaches (Rundle and Dewar, 2006). However, there are many development projects that require a certain degree of flexibility in order to ensure a high responsiveness to changes in the development context, e.g. projects with a strong customer focus and few restrictive constraints (Yusuf et al., 1999).

In general, agile and plan-driven approaches can be distinguished by a variety of factors. Agile approaches aim to quickly generate customer value in a highly dynamic development environment with small development teams, direct communication within the team and qualitative controlling. Plan-driven approaches rely on stability in the project plan and in the environment, are suitable for development projects in larger teams with documented project planning and exclusively need-based customer integration. (Boehm and Turner, 2003)

\subsection{Implementation of agile approaches in companies of mechatronic development}

More and more companies work with agile approaches in their projects (Goevert et al., 2018, p. 10). As a result, implementation strategies are being increasingly focused in the mechatronic areas. When implementing agile processes, a distinction must be made between cultural and technical agility (Diebold et al., 2015, p. 121-122). Diebold et al. (2015) regard methods as technical agility and the principles as well as behaviours as cultural agility. In order to carry out the process of change towards agile development, the role of an agile coach is required from the outset (Parizi et al., 2014, p. 246). The three phases are preparation phase (determining the action plan and maturity of the company), adaptation phase (introducing methods with practical relevance) and adjustment phase (adjustment methods to the company context) (Parizi et al., 2014, p. 247-248).

Parizi has a strong focus on introduction. In contrast, Moreira (2013) focuses on the entire process. Moreira (2013, p. 59-69) defines a ready, implement, coach, and hone agile deployment model (RICH model). In the implementation phase, employees should understand why agile methods are used as well as adopt and adapt them to the corresponding situations (Moreira (2013, p. 63)).

In addition to the specific agile implementation strategies, general implementation strategies such as Kotter's 8-step process (Kotter 2006, p. 4) must also be considered.

\subsection{Agile studies in practice}

The current popularity of agile approaches can be seen in a large number of case studies investigating the application of agile approaches in companies, in addition to the extensive literature on this topic. The focus here is mostly on software projects (Moe et al., 2010; Melo et al., 2013) in which the potentials and challenges (Estler et al., 2014) of Scrum are examined in different scaling levels (Bjarnason et al., 2011). Although the number of case studies in the field of mechatronic system development is much lower (Eklund and Berger, 2017; Eliasson et al., 2014), agility is also becoming increasingly important in the development of physical products. In a student development project, for example, it was shown that as the project progresses and the product matures, prototyping should increasingly address the technical implementation of features in depth, while at the same time optimizing and extending features should be carried out. The latter in particular can be supported by agile principles, while technical detailing follows more classical approaches. In addition, it could be shown that teams that develop conventionally refine the initial project idea, while agile teams increased the customer value by continuously checking and adapting features over the entire course of the project. (Bohmer et al., 2017) A further case study showed that the combination of model-based development with agile approaches counteracts the physical hurdles from mechatronic system development for high reactivity. Thus short iteration cycles could be intercepted by virtual test environments and the further development of necessary knowledge could be generated early in the process. In contrast to the hardware test, however, a large number of estimates had to be made in this project, making the development risk difficult to control. (Eliasson et al., 2014) 


\section{RESEARCH HYPOTHESISES AND RESEARCH DESIGN}

The aim of this research project is to derive statements regarding the handling of agile practices, principles, values and mindsets in the field of mechatronic system development and to outline a status quo regarding the implementation success of agile approaches. The contribution does not presuppose, that the goal of an organization must be to be as agile as possible in every development project.

Different hypotheses are derived from the fact that agile approaches originate from software development and are only slightly adapted to the conditions of mechatronic system development. In this research work, a comparison should be made between the associated hypotheses and the way industry works. The hypotheses results from the authors working impressions with the industry, literature research, and the online survey of Goevert et al. (2018). These hypotheses are the following:

- If companies develop agile, a large part of the companies in the field of mechatronic system development use agile practices, but culture and mindset are currently not agile (doing vs. being agile).

- The challenges to establishing agile approaches in the field of mechatronic system development must be limited to a small number of main causes.

- $\quad$ Design methods can limit agility in the development team because agile approaches do not seamlessly integrate these methods.

- The more systematic agility is introduced the more sustainable agile approaches are integrated. In order to gain insights on the basis of the formulated research hypotheses, this article is based on the Design Research Methodology (DRM) according to Blessing and Chakrabati (2009). In addition to the Research Clarification, the study includes an assessment of needs in practice and is therefore DRM Type 1 (Blessing and Chakrabarti, 2009, p. 18) with a focus on an understanding of certain interrelationships. With the aim of gaining an initial understanding of the key aspects described in the hypotheses, the research method used was an interview study with 18 participants from different industries and departments.

Table 1. Overview of categories (left) and questions (right) in the interview

\begin{tabular}{|c|c|}
\hline $\begin{array}{l}\text { Area the questions } \\
\text { belong to }\end{array}$ & Questions \\
\hline \multirow{4}{*}{$\begin{array}{l}\text { Understanding about } \\
\text { agile development in } \\
\text { companies }\end{array}$} & What do you understand by agile development? \\
\hline & $\begin{array}{c}\text { Do you (your team/department) develop agile according to your } \\
\text { understanding? }\end{array}$ \\
\hline & Do you use agile techniques (SCRUM, Design Thinking, Lean Startup,...)? \\
\hline & $\begin{array}{l}\text { Why do you abandon agile techniques in certain situations? What are the } \\
\text { reasons for this? }\end{array}$ \\
\hline \multirow{4}{*}{$\begin{array}{l}\text { The correlation between } \\
\text { agile approaches and } \\
\text { design methods }\end{array}$} & $\begin{array}{c}\text { Do you use design methods such as creativity techniques, evaluation } \\
\text { methods, system analysis methods? }\end{array}$ \\
\hline & What impact does applying the methods you mentioned have on agility? \\
\hline & $\begin{array}{c}\text { In various development situations, do you independently select the } \\
\text { appropriate methods or are these given to you by project managers, internal } \\
\text { processes or similar? }\end{array}$ \\
\hline & $\begin{array}{l}\text { In your opinion, how much prior knowledge (process knowledge and } \\
\text { product knowledge) from previous product development projects flows into } \\
\text { the development of the current product (in \%). }\end{array}$ \\
\hline \multirow[t]{2}{*}{ Limits of agility } & $\begin{array}{l}\text { In your experience, what are the limits of agile methods, processes and } \\
\text { development? }\end{array}$ \\
\hline & If possible: Please give one example each of the limits you have identified \\
\hline \multirow{5}{*}{$\begin{array}{l}\text { Implementation of agile } \\
\text { approaches }\end{array}$} & How was agile development introduced in your company? \\
\hline & $\begin{array}{l}\text { Was agile development methodically introduced or was there a strategy that } \\
\text { was pursued? }\end{array}$ \\
\hline & How was the agile mindset created for employees and colleagues? \\
\hline & $\begin{array}{l}\text { Was the introduction of agile approaches successful from your point of } \\
\text { view and are there still challenges at the moment? }\end{array}$ \\
\hline & $\begin{array}{l}\text { Would you do something different when introducing agile approaches if } \\
\text { you introduced agile approaches again? }\end{array}$ \\
\hline
\end{tabular}


The hypotheses led to the targeted generation of interview questions. A broad overview across different industries should be generated. For this reason, an interview study with open-ended questions was better suited than a quantitative questionnaire with narrow answers, which partly do not fit the target group due to the industry. The interview consisted of socio-demographic questions and 15 content-related questions with open answers (see Table 1., left column). All interviewees deal with the agile development in their companies. The companies were selected on the basis that they were from the field of mechatronic system development and that they should cover various industries. Also, the size of the companies should not be limited to a certain extent. The participants came from the following industries: automotive industry (4 participants), general mechanical engineering ( 3 participants), power tools and equipment construction ( 2 participants), engineering services ( 2 participants), special mechanical engineering (2 participants), writing instruments industry, power engineering, automation technology, medical technology and household appliance technology (1 participant each).

\section{RESULTS AND FINDINGS}

This section first describes the conception of the interview study. Then the following aspects are addressed: agile values, goals of the implementation, compatibility of agile methods and design methods, differences of the implementation, and key facts. The study was carried out and evaluated according to the following procedure: With the agreement of the participants, the interviews were digitally recorded and subsequently transcribed word for word by the interviewers. Already at this stage, the answers were assigned to the questions asked in a database, which was necessary as the answers sometimes covered several questions at the same time. The interpretation of the answers was carried out with regard to the hypotheses. For example, recurring keywords or elements with recurring content were marked separately and key aspects were identified. The aim was not to clearly verify or falsify the hypotheses. Rather, an initial overview of the current status of the individual topics should be identified.

\subsection{Realization of agile values}

First, the participants were asked about their understanding of agility combined with the way of the execution of agile practices in order to deduce whether they can be classified at the level of agile mindsets, the implementation of agile values, the 12 principles, or only the application of agile practices with regard to the literature. The classification is visualized in Figure 1.

The statements were assigned to the individual levels of agility (Moreira, 2013, p. 8) on the basis of their focal points. Only two participants could be assigned to an agile mindset or the implementation of agile values on the basis of their statements:

"Agile development procedures are procedures that are formulated in accordance with the agile manifesto." "... moving away from high planning costs at the beginning ..."; "There are projects in which the teams follow the idea of the agile manifesto, although no specific approach can be generalized here."

The majority of the respondents were assigned to the level of implementation of the principles or practices, as their understanding and execution on the one hand only aimed at these two categories and on the other hand the actual implementation contradicted the agile mindset: "... developing in sprints, continuous planning after each iteration, no shortening of overall project duration". "After all, it's the application of agile project management methods to the development process, but even there you have to be careful not to mix content and procedures. That's actually it already is. More is not behind it if you are honest."

The statements lead directly to the question whether purely agile development with the existing approaches is practical for mechatronic system development, or whether existing approaches are unsuitable due to their origins in software development to create a consistent agile mindset for companies that develop physical products. It should be stressed that the majority of respondents are currently in the process of implementing agile development in their company. 


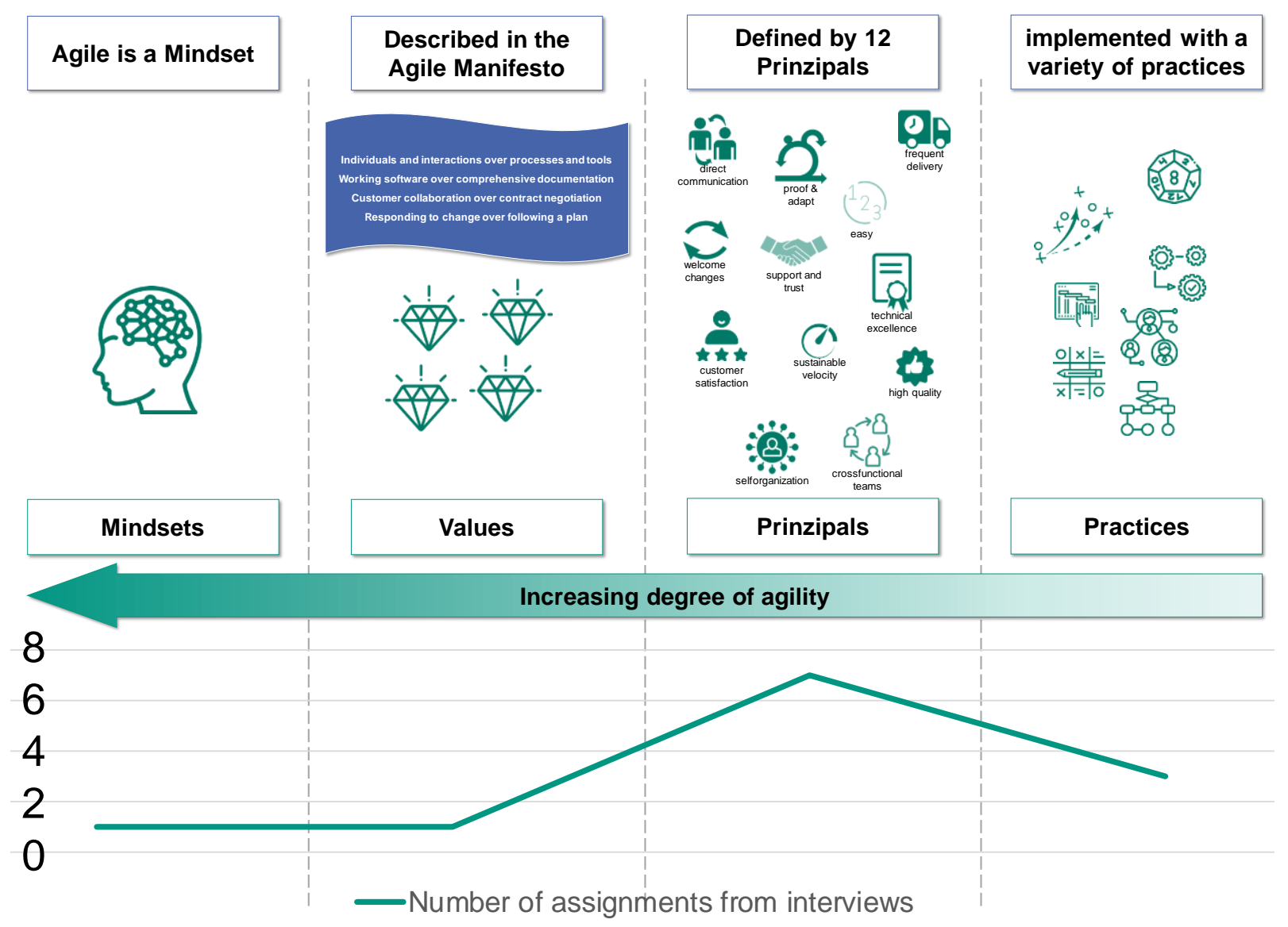

Figure 1. Assignment of participants to one of the levels of agility on the basis of their agile understanding and execution. Illustration according to Schaaf (2017)

\subsection{Goals, current status, and limits of agile development implementation}

For the interview participants, agile development means reacting to unpredictable situations and adapting the process to determining factors. The focus is on effective and efficient action and strong customer integration. For customer integration, a continuous gain of knowledge and added value for the customer is created in small and iterative steps. This takes place in self-organized teams, whereby more responsibility lies with the experts.

Out of the 18 participants, eight said that they develop agile according to their definition of agile. Related to the projects in which agile methods are used. Six of the participants said that they develop agile only partially. As reasons for this, they mentioned that responsibility is not given, that tasks and user stories are defined from the beginning, that there is no defined agile procedure or that they are currently still in the implementation process.

On the one hand limits of agile development arise on the technical level and on the other hand on the cultural level. On the cultural level it is especially the rethinking from phase-oriented to agile across all levels. Agile needs the support of the management, because agile development can be introduced only so far, as it is carried by the management, and must be lived also on the working level and the coworkers may not be overwhelmed. The limits of the technical level, are often standardized frameworks. For example, companies have prescribed development processes or other departments such as controlling, which focuses on detailed planning. Other examples are that people do not work $100 \%$ on a project as described in the literature, interfaces to non-agile areas and the application of agile methods in large projects lead to challenges.

In addition, it can be deduced from the interview that, the interviewees can be divided into two groups. There is one group that wants to make the very formalized process more agile through agile development and there is a second group that wants to implement a bit more structure into development processes through agile development. 


\subsection{Correlation between agile approaches and design methods}

All respondents stated that they had integrated at least selected mechanisms of agile approaches into their everyday development work. In addition, all participants also stated that they use different design methods in the product development process. These range from simple methods such as brainstorming, the 6-3-5 method and the morphological box to utility analyses and larger methods such as FMEA or system analyses. 14 of the 18 participants saw no disadvantages to agile processes through the implementation of design methods. However, three of the participants found certain methods to be extremely extensive and therefore heavy and inflexible. For example, two participants stated that an FMEA requires an immense amount of execution effort, which ties up resources and reduces the responsiveness of the development team during the execution. One participant stated that, especially with larger system analyses, a high degree of interaction between components is identified quickly, which in turn requires increased coordination with other colleagues. These colleagues, in turn, are sometimes not agile, which can lead to coordination problems and loss of response time. In addition, the dimensions of this analysis can become intransparent quickly. One of the participants stated that prescribed methods from a certain development process had to be applied in the process at scheduled points in time. This idea contradicts the flexible core of agile procedures.

In summary, it can be concluded that methods with short execution times and low preparation and postprocessing efforts do not in any way create obstacles to the agility of development teams. However, methods with high implementation efforts such as FMEA are perceived as agility inhibitors - such methods, must not be neglected in the process of mechatronic system development. Methods with a technical focus such as system analyses are also perceived as not promoting agility, since high system interactions lead to excessive coordination efforts in the project.

\subsection{Differences of systematical and non-systematical implementation of agile}

The interviewer asked about the implementation procedure. Very few of them pursued a comprehensive implementation strategy. In many companies the agile development was introduced bottom up. The agile development was "simply" applied, tried out and analysed to see what works and what does not work. One of them said he had introduced agile development without calling it agile.

In companies where agile development was and is strategically introduced, there is often a whole team dealing with agile development. Team members spread agile development through information days, internal trainings and by working as coaches in agile development projects. Often the feeling arose in the interviews that the more intensively the company is concerned with agile development, as higher is the level of the interviewees on the agile levels.

Since a distinction must be made between doing and being agile, the introduction of the agile mindset was asked in particular. The mindset was partly created by doing or by living the agile culture. A concrete solution that has been mentioned by different companies is to identify highly motivated colleagues with regard to agile development and to carry out a pilot project with them. Through the positive reports also further employees are convinced of the agile development. In some cases, external reports also reported on successful agile development.

Most of the interviewees see challenges in the implementation of agile approaches in the area of top management. They have to live the agile development themselves and let it live. External partners and general conditions are also seen as challenging, as is the introduction of agile development in hardware series development.

\subsection{Key-facts}

On an abstract level, the interviewees have a very similar understanding of agile development. In the implementation, the understanding is not fully lived or cannot be fully lived due to the framework conditions.

All interviewed companies use elements from Scrum. Often these are single elements or in a modified form. One company indicated not to use the terms. The procedure is nevertheless similar to Scrum.

Most companies use mechatronic development methods in combination with agile methods and especially creativity methods. In most cases this does not influence the agility from the interviewee's point of view.

Basic methods and the basic process are prescribed company-wide. In detail, the teams often select further methods. 
A high proportion of prior knowledge from previous projects or products is often incorporated into the projects. The companies reported up to $90 \%$. This is also the case with innovative projects and should be supported by agile approaches.

\section{DISCUSSION AND EVALUATION}

The findings in this article are intended to provide impulses for further research activities. Thus these are not understood as generally valid findings, since on the one hand the sample only comprises 18 participants and on the other hand the answers are not measurable and were evaluated by the team of authors using their own interpretations. In the following, it will be discussed to what extent the hypotheses from section 3 are confirmed or refuted by the interviews.

However, the insights gained are based on the practical assessment of real mechatronic system development in companies in various sectors. It can be stated that companies in the field of mechatronic system development are currently at the beginning of the integration of agile procedures. Companies are taking over individual elements of established agile approaches from software development, such as development in sprints, which is e.g. integrated into a stage gate process. By integrating agile approaches, companies expect increased flexibility in the development process and a stronger customer focus. In addition, various development methods are integrated into the product development process, whereby a number of important methods exist, which are very technical and complex to implement. These methods are currently perceived as challenges to agile approaches.

Another hypothesis was that the challenges for the implementation of agile approaches in the field of mechatronic system development can be limited to a few causes. The interviews often revealed three challenges: interfaces to other areas that do not develop agile, the necessary support of top management is missing and the understanding of the environment, e.g. from customers, is not yet fully given. This means that the challenges can be limited to a few, but often every company still has to contend with individual challenges, such as employees with a long period of employment being difficult to enthuse about agile development.

When implementing agile approaches in their own development processes, it was found that companies do not follow a general procedure, but use different strategies (e.g. implementation of a pilot project). Often it is an unsystematic try and error process. Many of the interviewees stated that they would do so again if they introduced agile development in the company again. The interviewees also achieved successes and improved the respective development processes. Nevertheless, it was perceived during the interviews that in a systematic introduction the three challenges from the previous paragraph were less significant and often a higher level of agility was achieved. However, it has to be taken into account that it may not be the goal of the companies to achieve the highest level of agility but to design their development process in the best possible way and a lower level of agility may be advantageous.

In general, it can be stated that the simple adoption of an agile approach from software development into the processes of mechatronic system development is not easily possible and not always sensible due to the diverging framework conditions. In addition, companies do not aim to be as agile as possible, but tend to achieve a level of agility in the development process that is appropriate to the situation and demands of development teams. Furthermore, the identified phenomena are not dependent on the industry or the size of a company. In order to support companies in their development processes in the best possible way with regard to the course of development and planning activities, scientifically modelled approaches should understand and integrate the current processes in the companies in order to ensure the best possible orientation towards reality. In addition, implementation strategies should not be formulated in general terms, but rather modelled in accordance with the needs and goals of the company. The knowledge gained also requires further research and deepening in order to identify cross-company and cross-industry needs and phenomena.

\section{CONCLUSION}

The paper gives an insight into the current status of agile mechatronic system development at 18 companies from 10 different industries. The interview guide includes sociodemographic questions and 15 questions on agile development. These have the four focus areas: understanding about agile development, correlation between agile approaches and design methods, limits of agility, and implementation of agile approaches. 
A very uniform basic understanding of agile development was identified, even if it varies in implementation. Often the implementation is based on methods and rarely on a strongly pronounced agile mindset. This often results in an agile doing and rarely in an agile being. However, it has to be considered that it is not necessarily the goal of the companies to achieve the highest degree of agility but to improve their development process in total and they manage that.

In the implementation of agile development, top management was often cited as a challenge, as agile development quickly reaches its limits without the support of managers.

In almost all companies of the interview partners, methods from software development, especially modified forms of Scrum, are implemented in mechatronic system development. The pure observance of agile principles and values and the development of new methods based on these principles has only partly taken place in companies so far.

Based on the interviews, the next steps will be in-depth interviews in the four focus areas. Furthermore, it is the goal to develop methodologies and strategies that support the overcoming of challenges in the area of interfaces and a holistic implementation of the agile approach. This should not only take place on the method level but also on the principles and values of agile development. Thus an agile being can be created in the company and not just an agile doing. In addition, further research activities are carried out to support development teams in identifying the degree of complexity of the problem situation. This is intended to support developers in their decision to focus more on phase-oriented or agile approaches to solving a problem and thus follow a procedure adapted to the situation.

\section{REFERENCES}

Albers, A., Heimicke, J., Walter, B., Basedow, G.N., Reiß, N., Heitger, N., Ott, S. and Bursac, N. (2018), "Product Profiles. Modelling customer benefits as a foundation to bring inventions to innovations", Procedia CIRP, Vol. 70 No. 1, pp. 253-258. https://doi.org/10.1016/j.procir.2018.02.044

Bjarnason, E., Wnuk, K. and Regnell, B. (2011), “A case study on benefits and side-effects of agile practices in large-scale requirements engineering", in Unknown (Ed.), Proceedings of the 1st Workshop on Agile Requirements Engineering, Lancaster, United Kingdom, 7/26/2011 - 7/26/2011, ACM, New York, NY, pp. $1-5$.

Blessing, L.T.M. and Chakrabarti, A. (2009), DRM, a design research methodology, Springer, Dordrecht, London.

Boehm, B. and Turner, R. (2003), "Using risk to balance agile and plan- driven methods", Computer, Vol. 36 No. 6, pp. 57-66.

Bohmer, A.I., Schweigert, S., Devecka, J., Grauvogl, C., Becerril, L., Bahrouni, Z. and Lindemann, U. (2017), "Towards agile development of physical products a startup case study", in Jardim-Gonçalves, R. (Ed.), "Engineering, technology \& innovation management beyond 2020: new challenges, new approaches". 2017 International Conference on Engineering, Technology and Innovation (ICE/ITMC) conference proceedings, Funchal, 6/27/2017 - 6/29/2017, IEEE, Piscataway, NJ, pp. 78-85.

Cooper, R.G. and Sommer, A.F. (2016), "The Agile-Stage-Gate Hybrid Model. A Promising New Approach and a New Research Opportunity", In: J Prod Innovation Management Vol. 33 No. 5, S. 513-526. https://doi.org/10.1111/jpim.12314.

Denning, S. (2013), "Why Agile can be a game changer for managing continuous innovation in many industries", Strategy \& Leadership, Vol. 41 No. 2, pp. 5-11.

Diebold, P., Küpper, S. and Zehler, T. (2015), Nachhaltige Agile Transition: Symbiose von technischer und kultureller Agilität. Projektmanagement und Vorgehensmodelle 2015, pp. 121-126.

Eklund, U. and Berger, C. (2017), "Scaling agile development in mechatronic organizations - a comparative case study”, in 2017 IEEE/ACM 39th International Conference on Software Engineering: Software engineering in practice track: ICSE-SEIP 2017 20-28 May 2017, Buenos Aires, Argentina proceedings, Buenos Aires, 5/20/2017 - 5/28/2017, IEEE, Piscataway, NJ, pp. 173-182.

Eliasson, U., Heldal, R., Lantz, J. and Berger, C. (2014), “Agile Model-Driven Engineering in Mechatronic Systems - An Industrial Case Study”, in Dingel, J. (Ed.), Model-driven engineering languages and systems: 17th international conference, MODELS 2014, Valencia, Spain, September 28- October 3, 2014; proceedings, Lecture notes in computer science Programming and software engineering, Vol. 8767, Springer, Cham, pp. 433-449.

Estler, H., Nordio, M., Furia, C.A., Meyer, B. and Schneider, J. (2014), “Agile vs. structured distributed software development: A case study”, Empirical Software Engineering, Vol. 19 No. 5, pp. 1197-1224.

Fowler, M. and Highsmith, J. (2001), “The Agile Manifesto”, Softw. Dev. Vol. 9, pp. 28-35. 
Goevert, K. Lindner, M. and Lindemann, U. (2018), "Survey on agile methods and processes in physical product development.” In: Iain Bitran, Steffen Conn, Eelko Huizingh, Kokshagina, O., Torkkeli, M. und Tynnhammar, M. (Hg.): ISPIM Innovation Forum: The Innovation Game: Base Hits, Not Home Runs.

Hofert, S. (2016), Agiler führen. Springer, Wiesbaden.

Kotter, J.P. (2006), "Leading Change.” Why Transformation Efforts Fail

Moe, N.B., Dingsøyr, T. and Dybå, T. (2010), “A teamwork model for understanding an agile team: A case study of a Scrum project”, Information and Software Technology, Vol. 52 No. 5, pp. 480-491.

Moreira, M.E. (2013), Being Agile: Your Roadmap to Successful Adoption of Agile, Apress, Berkeley, CA, s.l.

O. Melo, C., S. Cruzes, D., Kon, F. and Conradi, R. (2013), "Interpretative case studies on agile team productivity and management", Information and Software Technology, Vol. 55 No. 2, pp. 412-427.

Parizi, R.M., Gandomani, T.J. and Nafchi, M.Z. (2014), "Hidden Facilitators of Agile Transition: Agile Coaches and Agile Champions." in 8th Malaysian Software Engineering Conference (MySEC), Langkawi, Malaysia.

Petersen, K. and Wohlin, C. (2010), "The effect of moving from a plan-driven to an incremental software development approach with agile practices", Empirical Software Engineering, Vol. 15 No. 6, pp. 654-693.

Plattner, H., Meinel, C. and Leifer, L. (2011), Design Thinking: Understand - Improve - Apply, Springer Berlin Heidelberg, Berlin, Heidelberg.

Ranganath, P. (2011), “Elevating Teams from 'Doing' Agile to 'Being' and 'Living' Agile”, in 2011 Agile Conference (AGILE): 7 - 13 Aug. 2011, Salt Lake City, Utah, Salt Lake City, UT, USA, 07.08.2011 13.08.2011, IEEE, Piscataway, NJ, pp. 187-194.

Rebentisch, E., Conforto, E.C., Schuh, G., Riesener, M., Kantelberg, J., Amaral, D.C. and Januszek, S. (2018), “AGILITY FACTORS AND THEIR IMPACT ON PRODUCT DEVELOPMENT PERFORMANCE”, in International Design Conference - Design 2018, pp. 893-904.

Reichwald, R. and Piller, F. (2009), "Interaktive Wertschöpfung: Open Innovation”, Individualisierung und neu Formen der Arbeitsteilung, 2nd ed. Gabler Verlag, Wiesbaden.

Rundle, P.J. and Dewar, R.G. (2006), "Using return on investment to compare agile and plan-driven practices in undergraduate group projects", in Osterweil, L.J. (Ed.), Proceedings of the 28th international conference on Software engineering, Shanghai, China, 20.05.2006 - 28.05.2006, ACM, New York, NY, p. 649.

Schaaf, A. (2017), “Agiles Mindset als Infografik”, available at: https://key2agile.de/agiles-mindset-infografik/ (accessed 28 October 2018).

Schmidt, T.S., Weiss, S. and Paetzold, K. (2017), “Agile Development of Physical Products. An Empirical Study about Motivations, Potentials and Applicability", University of the German Federal Armed Forces.

Schmidt, T.S., Weiss, S. and Paetzold, K. (2018), "Expected vs. real effects of agile development of physical products. apportioning the hype", in International design conference - design 2018, pp. 2121-2132.

Schuh, G.; Dolle, C.; Diels, F.; Kuhn, M. (2018): Methodology for Determining Agile Product Scopes in Development Projects. In: 2018 Portland International Conference on Management of Engineering and Technology (PICMET). Honolulu, HI, 19.08.2018 - 23.08.2018: IEEE, S. 1-9.

Schwaber, K. and Sutherland, J. (2017), "The Scrum Guide".

Yusuf, Y.Y., Sarhadi, M. and Gunaserakan, A. (1999), “Agile manufacturing: The drivers, concepts and attributes”, International Journal of Production Economics, Vol. 62 No. 1, pp. 33-43. 